\title{
Mechanical suppression of osteolytic bone metastases in advanced breast cancer patients: a randomised controlled study protocol evaluating safety, feasibility and preliminary efficacy of exercise as a targeted medicine
}

Nicolas H. Hart ${ }^{1,2,3^{*}}$ (D), Daniel A. Galvão ${ }^{1,3}$, Christobel Saunders ${ }^{4,5,6}$, Dennis R. Taaffe ${ }^{1,3,10}$, Kynan T. Feeney ${ }^{1,3,4,7}$, Nigel A. Spry ${ }^{1,3,6,8}$, Daphne Tsoi ${ }^{1,3,4,7}$, Hilary Martin ${ }^{9}$, Raphael Chee ${ }^{1,3,6,8}$, Tim Clay ${ }^{4,8}$, Andrew D. Redfern ${ }^{6,9}$ and Robert U. Newton 1,3,10

\begin{abstract}
Background: Skeletal metastases present a major challenge for clinicians, representing an advanced and typically incurable stage of cancer. Bone is also the most common location for metastatic breast carcinoma, with skeletal lesions identified in over $80 \%$ of patients with advanced breast cancer. Preclinical models have demonstrated the ability of mechanical stimulation to suppress tumour formation and promote skeletal preservation at bone sites with osteolytic lesions, generating modulatory interference of tumour-driven bone remodelling. Preclinical studies have also demonstrated anti-cancer effects through exercise by minimising tumour hypoxia, normalising tumour vasculature and increasing tumoural blood perfusion. This study proposes to explore the promising role of targeted exercise to suppress tumour growth while concomitantly delivering broader health benefits in patients with advanced breast cancer with osteolytic bone metastases.

Methods: This single-blinded, two-armed, randomised and controlled pilot study aims to establish the safety, feasibility and efficacy of an individually tailored, modular multi-modal exercise programme incorporating spinal isometric training (targeted muscle contraction) in 40 women with advanced breast cancer and stable osteolytic spinal metastases. Participants will be randomly assigned to exercise or usual medical care. The intervention arm will receive a 3-month clinically supervised exercise programme, which if proven to be safe and efficacious will be offered to the control-arm patients following study completion. Primary endpoints (programme feasibility, safety, tolerance and adherence) and secondary endpoints (tumour morphology, serum tumour biomarkers, bone metabolism, inflammation, anthropometry, body composition, bone pain, physical function and patient-reported outcomes) will be measured at baseline and following the intervention.

(Continued on next page)
\end{abstract}

\footnotetext{
* Correspondence: n.hart@ecu.edu.au

'Exercise Medicine Research Institute, Edith Cowan University, 270 Joondalup

Drive, Joondalup, Perth, Western Australia 6027, Australia

${ }^{2}$ Institute for Health Research, University of Notre Dame Australia, Perth, WA,

Australia

Full list of author information is available at the end of the article
}

(c) The Author(s). 2018 Open Access This article is distributed under the terms of the Creative Commons Attribution 4.0 International License (http://creativecommons.org/licenses/by/4.0/), which permits unrestricted use, distribution, and reproduction in any medium, provided you give appropriate credit to the original author(s) and the source, provide a link to the Creative Commons license, and indicate if changes were made. The Creative Commons Public Domain Dedication waiver (http://creativecommons.org/publicdomain/zero/1.0/) applies to the data made available in this article, unless otherwise stated. 


\begin{abstract}
(Continued from previous page)
Discussion: Exercise medicine may positively alter tumour biology through numerous mechanical and nonmechanical mechanisms. This randomised controlled pilot trial will explore the preliminary effects of targeted exercise on tumour morphology and circulating metastatic tumour biomarkers using an osteolytic skeletal metastases model in patients with breast cancer. The study is principally aimed at establishing feasibility and safety. If proven to be safe and feasible, results from this study could have important implications for the delivery of this exercise programme to patients with advanced cancer and sclerotic skeletal metastases or with skeletal lesions present in haematological cancers (such as osteolytic lesions in multiple myeloma), for which future research is recommended.
\end{abstract}

Trial registration: anzctr.org.au, ACTRN-12616001368426. Registered on 4 October 2016.

Keywords: Tumour suppression, Tumour growth, Resistance training, Aerobic training, Isometric training, Muscle activity, Exercise medicine, Advanced cancer, Bone metastases,

\section{Background}

Bone metastases are generally incurable and clinically problematic, yet are present in over $80 \%$ of patients with advanced breast cancer $[1,2]$, representing a debilitating stage of disease with very poor patient prognoses during palliation, and one of the leading causes of breast cancer mortality among women worldwide [3-5]. Osteolytic (lytic) bone metastases, in particular, present a considerable challenge to patients and clinicians due to rapid microarchitectural deterioration of affected skeletal sites through tumour-driven dysregulation of bone metabolic activity in favour of excess resorption [1, 6, 7]. Metastatic breast carcinomas commonly deposit in trabecular (cancellous) regions of bone [6, 8-10], such as the skull, ribs, spine, pelvis and proximal and distal segments of long bones, owing to their strong affinity to red bone marrow $[2,7,9,11]$. Of direct relevance, the majority of these skeletal structures are characteristically load-bearing [12-14], thus any accelerated bone loss and heightened fragility following tumoural infiltration [8, 10, 15-17] has immediate consequences for patients with cancer if left untreated or unmanaged. Consequently, this destructive skeletal process leads to increased patient morbidity and mortality, with heightened fragility, increased risk of spinal compression, potential development of hypercalcaemia, increased bone pain and increased fracture risk [7, 17-19]; whilst simultaneously creating a localised microenvironment conducive to tumoural growth and invasion within affected bone sites [20-23].

Chemotherapy, hormone therapy, radiotherapy and anti-resorptive medications are the primary therapeutic agents used in breast cancer palliation to delay disease progression, alleviate bone pain and associated symptoms, preserve skeletal integrity and extend survival [24-32]. Whilst effective, these treatments produce well-documented side effects to varying degrees, which can lead to dose limitation or cessation, subsequently restricting their full clinical utility. For example, patients with advanced breast cancer with bone metastases are provided with bone strengthening (anti-resorptive) medications such as bisphosphonates or denosumab to fortify bone through induced sclerosis leading to increments in bone density [33, 34]. While efficacious in the mid-term; long-term use of these medications themselves eventually generate skeletal fragility in the absence of a discontinuation period [35-37], which is not a clinically viable option for patients with advanced cancer and osteolytic bone metastases.

Bone is highly adaptive and osteogenically sensitive to its mechanical environment, principally through muscular contraction of neighbouring muscle, but also from impact and gravitational forces acting upon the skeleton during human movement and from external loads [12, 38, 39]. Up-regulation of osteoblastic activity through exercise may therefore allow mechanically driven regulation of bone metabolism (i.e. osteocyte-mediated coupling of osteoblast and osteoclast activity) to counteract tumour-driven dysregulation which could have two key benefits: (1) to preserve bone strength through anabolic morphological (material and structural) adaptations; and (2) to interfere with tumoural processes that blunt osteoblastic formation and promote osteoclastic resorption, thus potentially suppressing tumour growth in affected skeletal sites. Preclinical studies $[8,13,40,41]$ have explored this potential relationship in rodent orthotopic models, implanting human breast cancer cells into trabecular skeletal tissue in order to induce osteolysis in the load-bearing tibia. Impressively, when comparing loaded and non-loaded tumour-affected tibiae within host rodents, repeated bouts of externally controlled mechanical compression preserved skeletal integrity $(0 \%$ versus $71 \%$ degradation for loaded and unloaded conditions), blunted tumour-mediated osteolysis, and significantly suppressed tumour growth by approximately $80 \%$ $[8,13]$ in the absence of muscular influence. In addition to osteocyte-driven osteogenic signalling, the inextricable anatomical, mechanical, metabolic and pleiotropic link between muscle and bone [12, 38, 42, 43] provides 
another avenue of therapeutic osteogenic and anti-tumour potential not yet explored [14, 44-47]. The voluntary activation of muscle surrounding skeletal lesions may deliver anabolic cytokines and myokines (secretome cross-talk) to lesion sites $[14,44,45,48]$ to countenance catabolic tumour-mediated processes [46, 47, 49, 50]. Accordingly, mechanical signals propagated by muscle contraction may concurrently stimulate osteocyte-mediated metabolic activity and myokine-cytokine secretome cross-talk to promote osteogenesis while modulating tumoural behaviour and biology in order to slow tumour growth [14, 45, 48-51].

Human clinical trials have yet to be implemented in this space, owing to a historical and misplaced belief that patients with advanced cancer and bone metastases should be excluded from exercise programmes and synonymous research due to increased risk of skeletal complications or other potential adverse events [52-54]. Formative work by Galvão and colleagues [51, 55-58] demonstrated the safety and feasibility of delivering supervised exercise to patients with advanced prostate cancer and bone metastases, avoiding exercises that placed direct or targeted stress on bones with identified lesions. Separate work by Rief and colleagues $[59,60]$ demonstrated the safety and feasibility of physiotherapy-instructed spinal isometric training in isolation for patients undergoing palliative radiation therapy for spinal bone metastases, though in a small cohort of heterogeneous patients with cancer and disparate lesion types. Taken together, these studies illustrate the potential for preclinical studies to be translated to human patients; specifically models of advanced breast cancer with osteolytic bone metastatic disease. This is particularly important as animal studies do not always translate to the human condition, particularly in exercise-mediated bone adaptation studies, often due to poorly designed human trials for equivalency [12, 61-63].

Given that bone metastases remain one of the leading causes of breast-cancer-related deaths worldwide, additional and novel interventions to target osteolytic lesions in skeletal tissue are highly clinically relevant. Expanding on our prior work, the aim of this study is to (1) assess the safety and feasibility of a supervised and individually tailored resistance, aerobic and flexibility exercise programme that includes targeted spinal isometric training in patients with advanced breast cancer and osteolytic bone metastases; (2) explore the preliminary efficacy of the exercise programme to slow tumour growth and tumour biomarker activity in target osteolytic spinal lesions and (3) examine the broader efficacy of the exercise programme to preserve muscle and bone mass, improve physical fitness, enhance physical function, reduce cancer-related fatigue and increase quality of life. It is the working hypothesis of this study that the exercise programme will be safe and feasible; will show signs of tumoural suppression and/or favourable alterations in tumour biomarkers; and will lead to positive physical and psychosocial outcomes for patients. If successful, the outcomes of this trial will be used to improve clinical knowledge pertaining to exercise prescriptions for patients with advanced cancer who have metastatic carcinomas and high disease burden, and will be used as a foundation for future phase II and phase III efficacy-focused human clinical trials to establish the anti-cancer effects of exercise. It is anticipated that this new information will aid in the establishment and/or renewal of clinical exercise guidelines for the management of cancer across the disease spectrum.

\section{Methods}

\section{Study design}

This single-blinded (investigators blinded to group allocation), two-armed, randomised and controlled (supervised exercise versus usual medical care) explorative clinical trial will examine the feasibility, safety and preliminary efficacy of combining targeted spinal isometric training with modulatory, multi-modal exercise (M3EP-SIT) in women with advanced breast cancer and stable osteolytic spinal bone metastases. The exercise group (intervention arm) will receive an individually tailored and supervised 12-week exercise programme involving resistance, aerobic, flexibility and isometric exercises in addition to usual medical care. The control group will receive usual medical care only during this time and will be asked not to change their baseline levels of physical activity. However, following the trial, the control group will be offered the same exercise programme if proven to be safe and efficacious. This procedure has been shown to be an effective strategy to minimise study contamination, patient withdrawal or loss of patients to follow up in prior exercise oncology trials [14, $52,64-68]$.

\section{Recruitment}

Patients will be recruited by invitation of their cancer specialist (surgeon, radiation oncologist or medical oncologist) who will provide clinically eligible patients with a study information sheet and refer these patients to an independent study coordinator. If patients are interested in participation and their eligibility is confirmed, they will receive an informed consent document to read and sign in the presence of a study investigator and clinical research coordinator before undertaking baseline measurements prior to randomisation (Fig. 1).

\section{Randomisation}

Patients will be randomly allocated in a ratio of $1: 1$ to the two study arms: exercise or usual care, stratified by age $(\leq$ 60 years, $>60$ years), hormone receptor (HR) status (HR+, HR-) [69] and time since completion of palliative 


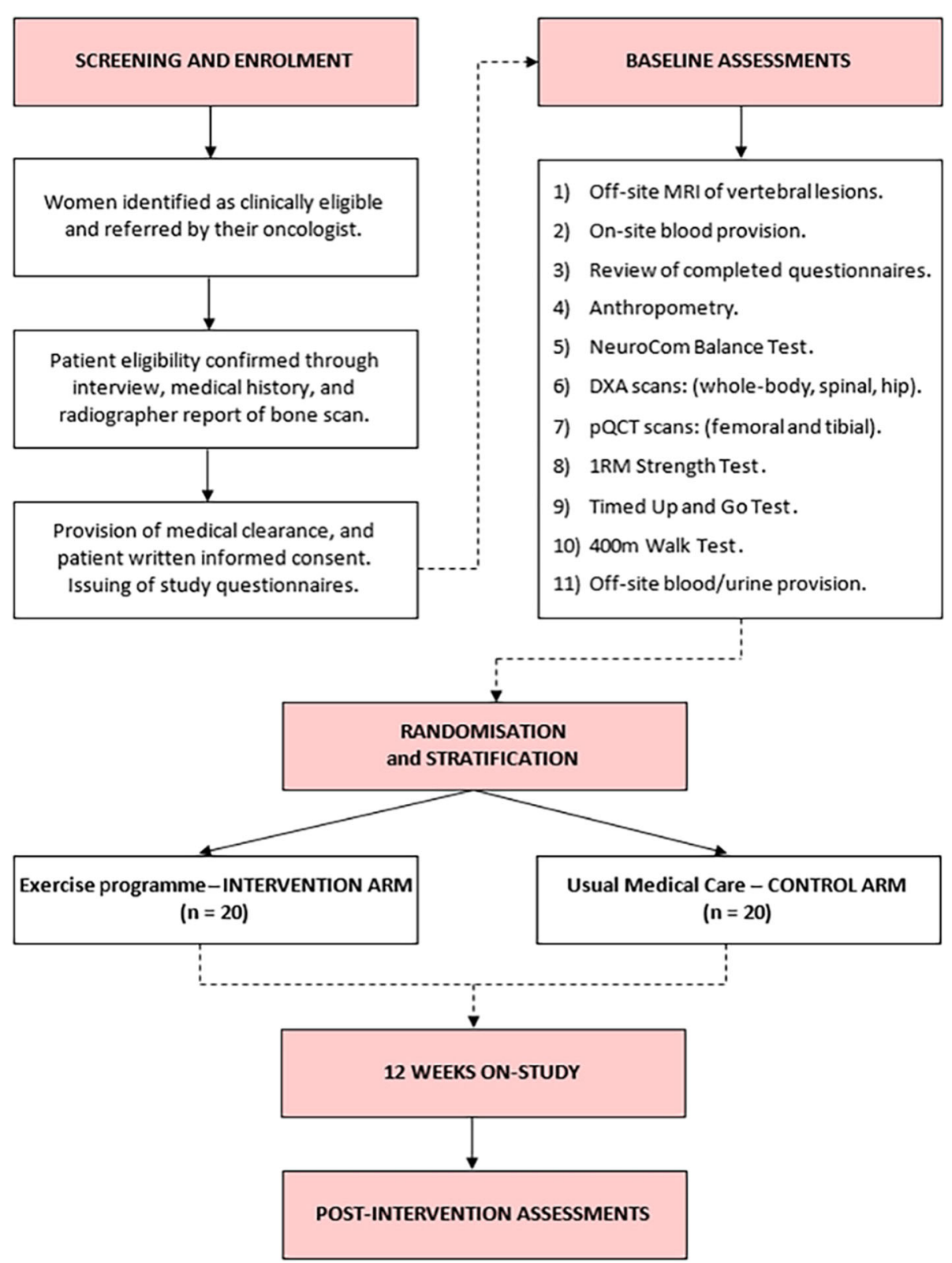

Fig. 1 Schematic overview of the study protocol. MRI, magnetic resonance imaging; DXA, dual-energy x-ray absorptiometry; pQCT, peripheral quantitative computed tomography; 1RM, one-repetition maximum

radiotherapy to target spinal lesions $(<3$ months, $\geq 3$ months) and/or time since commencing or changing hormone therapy and/or chemotherapy (<3 months, $\geq 3$ months). A research officer with no patient contact will be responsible for randomisation of patients into either group using a computer-generated code through a random-assignment programme. Study investigators and exercise physiologists conducting testing procedures will be blinded to group allocation. Only exercise physiologists outside the research team will be permitted to deliver the exercise intervention to participants in order to maintain integrity of the blinding process.

\section{Participants}

A total of 40 women (20 subjects per arm) with breast cancer and stable osteolytic bone metastases in cervical, thoracic and/or lumbar vertebrae will be invited to participate. They will be included if they have not engaged in regular exercise in the past 3 months (defined as undertaking structured aerobic and/or resistance training two or more times per week). Due to the novelty of this explorative clinical trial, our sample size is based on previous preclinical animal studies [13, 70-72], human pilot studies $[14,56,58,73,74]$ and consideration of the ability to recruit patients with advanced breast cancer 
and osteolytic bone metastases during the trial. Specifically, to achieve $80 \%$ power at an alpha level of 0.05 (two-tailed), 16 subjects per group are required to demonstrate a meaningful difference (effect size $\geq 1.0$ ) at the completion of the study for the primary endpoint, and most secondary endpoints. To account for an attrition rate of up to $25 \%, 40$ subjects will be randomised equally between the study arms (exercise, $n=20$; control, $n=20$ ).

Patients are permitted to receive radiotherapy for non-spinal bone metastases while enrolled in this trial. Patients require medical clearance prior to enrolment, therefore must achieve an Eastern Cooperative Oncology Group (ECOG) performance status $\leq 1$, and must not have any acute illness, significant bone pain or cardiovascular or neurological disorders that could inhibit exercise participation as judged by their managing physician. All participants must provide written informed consent prior to participation. Patients will be excluded from this trial if they are receiving experimental treatments. The protocol has been approved by the Human Research Ethics Committee (HREC) of Edith Cowan University (ECU), Project ID 14266 NEWTON; St John of God Hospitals (SJOG), Project ID 969 and Sir Charles Gairdner and Osborne Park Health Group (SCGOPHG), Project ID 2016-118. This trial is also registered with the Australia and New Zealand Clinical Trails Register (ANZCTR), Trial ID ACTRN-1261600136842.

\section{Measurements}

Primary and secondary endpoints will be measured at baseline (week 0), post-intervention (week 13) and through-out the 12-week on-trial period (Table 1).

\section{Primary Endpoint}

Feasibility Study and programme feasibility will be quantified through a series of multi-item categories including patient recruitment and trial completion, patient safety and tolerance and program adherence and compliance (Table 2). Programme safety will be assessed by recording the incidence and severity (grading) of adverse events and/or skeletal complications [18] throughout the on-trial period for the intervention and control arms in accordance with the common terminology criteria for adverse events (CTCAE) v5.0 criteria. Skeletal complications will include heightened bone pain at sites of known bone metastases and/or pathological skeletal fractures. The nature, severity and impact of bone pain will be examined using the Functional Assessment of Chronic Illness Therapy (FACIT) bone pain questionnaire at baseline and post intervention.

Programme tolerance, adherence and compliance will be assessed in the intervention arm only. Specifically, programme tolerance will be quantified by routinely measuring pre-session bone pain, muscle soreness and general fatigue at each exercise session by visual analogue scale (VAS, 0-10) and by recording post-session rating of perceived exertion (Borg scale, 010) and post-session tolerance (VAS, 0-10) after each exercise session. Programme adherence and compliance will be assessed using an exercise diary completed by the patient at all clinic-based and home-based exercise sessions to record volume of resistance training (weight lifted (kilogrammes), sets and repetitions), aerobic training (intensity (level), duration (minutes), speed (revolutions per minute), heart rate (maximum and average) and rating of perceived exertion), flexibility training (repetitions and hold time (duration)) and isometric training (repetitions and hold time (duration)) completed. These data will be compared to the prescribed and individualised exercise programme provided to each patient in order to establish programme adherence (completed versus missed sessions) and compliance (prescribed versus actual exercise completed for each training mode (resistance, aerobic, flexibility and isometric)).

\section{Secondary endpoints}

Tumour morphology Location of metastatic lesions will be initially identified through bone scans provided by the managing oncologist prior to referral to this study. Tumour morphology will be measured using axial T1-weighted magnetic resonance imaging (MRI) (1.5 T, Magnetom Essenza, Siemens, Victoria, Australia) in locations where osteolytic lesions have been identified in patients with bone metastases at either thoracic or lumbar spinal regions [75-78]. All patients will be scanned by the same radiologist using the same MRI machine and a standardised sequence and routine for scout and primary scan acquisition. Specifically, spinal bone metastases will be identified and confirmed using three preliminary axial scout scans in the sagittal plane to view the cervical, thoracic and lumbar regions, respectively (T2-weighted; imaging frequency $=63.66 \mathrm{~Hz}$; slice thickness $=3.0-4.0 \mathrm{~mm}$; spacing between slices $=3.6-6.0 \mathrm{~mm}$; echo train length $=16-21$; flip angle $=140-150^{\circ}$; acquisi-

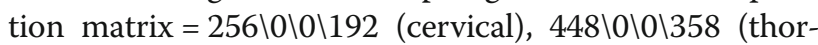

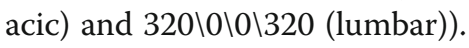

Primary scans of each affected vertebra will be performed in the transverse plane, capturing the vertebrae above and below to produce an image with three vertebrae in total (T1-weighted; imaging frequency $=63.66$ $\mathrm{Hz}$; slice thickness $=4.0 \mathrm{~mm}$; space between slices $=4.2$ $\mathrm{mm}$; echo train length $=3$; flip angle $=150^{\circ}$; acquisition matrix $=384 \backslash 0 \backslash 0 \backslash 307)$. Following the acquisition of images, tumour morphology (volume (cubic millimetres) and intensity (watts per steradian (W/sr))) will be examined for each slice using ITK-Snap (V3.6.0) image 
Table 1 Assessments of study feasibility

\begin{tabular}{|c|c|}
\hline Measures & Time of collection \\
\hline \multicolumn{2}{|l|}{ Recruitment and completion } \\
\hline - Referred patients & Trial completion \\
\hline - Eligible patients & Trial completion \\
\hline - Enrolled patients & Trial completion \\
\hline - Eligibility rate & Trial completion \\
\hline - Recruitment rate & Trial completion \\
\hline - Trial completions & Trial completion \\
\hline - Patient withdrawals & Trial completion \\
\hline - Patient drop-outs & Trial completion \\
\hline - Trial contamination & Trial completion \\
\hline \multicolumn{2}{|l|}{ Patient safety (control arm) } \\
\hline - Number of adverse events & Tri-weekly record \\
\hline - Severity of adverse events & Tri-weekly record \\
\hline - Number of skeletal complications & Tri-weekly record \\
\hline \multicolumn{2}{|l|}{ Patient safety (intervention arm) } \\
\hline - Number of adverse events & $\begin{array}{l}\text { At each exercise } \\
\text { session }\end{array}$ \\
\hline - Severity of adverse events & $\begin{array}{l}\text { At each exercise } \\
\text { session }\end{array}$ \\
\hline - Number of skeletal complications & $\begin{array}{l}\text { At each exercise } \\
\text { session }\end{array}$ \\
\hline \multicolumn{2}{|l|}{ Program tolerance (intervention arm) } \\
\hline - Pre-sessional bone pain & $\begin{array}{l}\text { At each exercise } \\
\text { session }\end{array}$ \\
\hline - Pre-sessional fatigue & $\begin{array}{l}\text { At each exercise } \\
\text { session }\end{array}$ \\
\hline - Sessional rating of perceived exertion & $\begin{array}{l}\text { At each exercise } \\
\text { session }\end{array}$ \\
\hline - Sessional tolerance & $\begin{array}{l}\text { At each exercise } \\
\text { session }\end{array}$ \\
\hline \multicolumn{2}{|l|}{ Program adherence (intervention arm) } \\
\hline - Number of completed sessions & Post intervention \\
\hline - Number of missed sessions & Post intervention \\
\hline \multicolumn{2}{|l|}{ Program compliance (intervention arm) } \\
\hline $\begin{array}{l}\text { - Prescribed vs. actual exercise completed (for } \\
\text { each exercise mode). }\end{array}$ & Post intervention \\
\hline $\begin{array}{l}\text { - Percent of total volume completed (for each } \\
\text { exercise mode). }\end{array}$ & Post intervention \\
\hline
\end{tabular}

analysis software [79] (Fig. 2). All images will be examined at the conclusion of the study by two independent researchers for consistency in analysis and to establish intra-rater and inter-rater reliability coefficients.

Biomarkers Metastatic tumour biomarkers, hypoxia-inducible factor 1-alpha (HIF-1 $\alpha)$ and transformation growth-like factor beta $(\mathrm{TGF}-\beta)$ will be serologically examined to measure tumoural hypoxic activity and growth activity respectively; identified as synergistic drivers of metastatic tumour progression [45, 80-84]. Fasted serological and first-void samples for urianalysis will also be collected within $48 \mathrm{~h}$ of baseline and post-intervention testing sessions to measure bone metabolic activity and systemic inflammation. Specifically, bone formation marker, amino-terminal propeptide of type 1 procollagen (P1NP); bone resorption marker, amino-terminal collagen type-I telopeptide (NTx); bone disorder marker, alkaline phosphatase (ALP), inflammation marker, C-reactive protein (CRP) and fasting glucose and lipid profiles will be examined. All fasted serological and first-void biomarkers will be collected in the morning, and assessed by the same accredited laboratory (Australian Clinical Laboratories, Perth, Western Australia).

Anthropometry Stature will be recorded to the nearest $0.1 \mathrm{~cm}$ using a wall-mounted stadiometer (Model 222, Seca, Hamburg, Germany), with body mass recorded to the nearest $0.1 \mathrm{~kg}$ using an electronic scale (AE Adams CPW Plus-200, Adam Equipment Inc., CT, USA), with body mass index (BMI) calculated as weight divided by height in metres squared $\left(\mathrm{kg} / \mathrm{m}^{2}\right)$. Waist and hip circumferences are defined as the mid-point between the 10th rib and the iliac crest and the level of the greater trochanter, respectively, with the waist-to-hip ratio calculated. Femoral length will be measured from the greater trochanter to the knee-joint axis and tibial length will be measured from the knee-joint axis to the medial malleolus. Waist circumference, hip circumference, femoral length and tibial length will be measured to the nearest $0.1 \mathrm{~cm}$ using a constant-tension, retractable measuring tape (Model 4414, Tech-Med Services, NY, USA). Stature, waist circumference and hip circumference will be measured in triplicate in each participant, with the average of each variable retained for analysis.

Musculoskeletal health Whole-body, segmental (axial and appendicular) and regional (spinal and total hip) scans will be performed to examine bone area (BA), areal bone mineral content (aBMC), areal bone mineral density (aBMD) and lean mass using dual-energy $\mathrm{x}$-ray absorptiometry (DXA; Hologic Discovery A, Waltham, MA, USA). Whole-body and appendicular segmentations will be analysed in accordance with Hart and colleagues [85]. Regional analyses (lumbar spine, total hip, femoral neck, trochanter, Wards triangle) will be performed in accordance with Hologic's manufacturer specifications [86].

Appendicular, non-lesion control sites will be scanned to quantify bone material, structure and strength using peripheral quantitative computed tomography (pQCT; XCT-3000, Stratec, Pzochienheim, Germany). Specifically, trabecular, cortical, marrow and total volumetric 
Table 2 Schedule of assessments at baseline and post intervention

\begin{tabular}{|c|c|c|}
\hline Measures & Baseline & Post intervention \\
\hline \multicolumn{3}{|l|}{ Tumour morphology (off-site) } \\
\hline - MRI: T1-axial & $x$ & $x$ \\
\hline \multicolumn{3}{|l|}{ Tumour biomarkers } \\
\hline - Blood: HIF-1a, TGF- $\beta$ & $x$ & $x$ \\
\hline \multicolumn{3}{|l|}{ Anthropometry } \\
\hline - Height (cm) & $x$ & \\
\hline - Weight (kg) & $x$ & $x$ \\
\hline - Waist circumference (cm) & $x$ & $x$ \\
\hline - Hip circumference (cm) & $x$ & $x$ \\
\hline - Femoral length (mm) & $x$ & \\
\hline - Tibial length (mm) & $x$ & \\
\hline - Body mass index $\left(\mathrm{kg} / \mathrm{m}^{2}\right)$ & $x$ & $x$ \\
\hline - Waist-to-hip ratio & $x$ & $x$ \\
\hline \multicolumn{3}{|l|}{ Body composition } \\
\hline - DXA: whole-body, spinal, hip & $x$ & $x$ \\
\hline - pQCT: femoral, tibial & $x$ & $x$ \\
\hline \multicolumn{3}{|l|}{ Physical assessments } \\
\hline - NeuroCom Balance Test & $x$ & $x$ \\
\hline - 1RM Strength Test (Leg Extension) & $x$ & $x$ \\
\hline - 400 m Walk Test & $x$ & $x$ \\
\hline - Timed Up and Go Test & $x$ & $x$ \\
\hline \multicolumn{3}{|l|}{ Other biomarkers (off-site) } \\
\hline - Blood: P1NP, ALP, CRP, fasting glucose and lipids & $x$ & $x$ \\
\hline - Urine: NTx & $x$ & $x$ \\
\hline \multicolumn{3}{|l|}{ Questionnaires } \\
\hline - Demographic and health history & $x$ & \\
\hline - Concomitant medications & $x$ & $x$ \\
\hline - Health-related quality of Life (SF-36) & $x$ & $x$ \\
\hline - Cancer-specific quality of life (EORTC: QLQ30, BR23) & $x$ & $x$ \\
\hline - Bone Pain (FACIT-BP) & $x$ & $x$ \\
\hline - Brief Symptom Index (BSI-18) & $x$ & $x$ \\
\hline - Insomnia Severity Index (ISI) & $x$ & $x$ \\
\hline - Godin Leisure-time Exercise & $x$ & $x$ \\
\hline \multicolumn{3}{|l|}{ Exercise programme } \\
\hline - Clinic exercise record sheet (prescribed vs. actual) & At each exercise session & \\
\hline - Home exercise record sheet (prescribed vs. actual) & At each exercise session & \\
\hline - Pre-session bone pain, muscle soreness and fatigue (VAS) & At each exercise session & \\
\hline - Post-session rating of perceived exertion and tolerance (VAS) & At each exercise session & \\
\hline
\end{tabular}

Abbreviations: HIF-1a hypoxia-inducible factor 1-alpha, TGF- $\beta$ transformation growth-like factor beta, DXA dual-energy x-ray absorptiometry, $p Q C T$ peripheral quantitative computed tomography, P1NP amino-terminal propeptide of type 1 procollagen, NTX amino-terminal collagen type-1 telopeptide, ALP alkaline phosphatase, CRP C-reactive protein, SF-36 Short Form-36, EORTC European Organisation for Research and Treatment of Cancer, FACIT-BP Functional Assessment of Chronic Illness Therapy-Bone Pain, VAS visual analogue scale

density (Tb.vBMD, Ct.vBMD, Ma.vBMD, Tt.vBMD); trabecular, cortical, marrow and total cross-sectional area (Tb.Ar, Ct.Ar, Ma.Ar, Tt.Ar); cortical thickness (Ct.Th); stress-strain index (SSIPOL); absolute fracture load (FL.Ab) and relative fracture load (FL.Rel) of the left femur (4\% and 33\% slices) and left tibia (4\%, 14\%, 38\% 

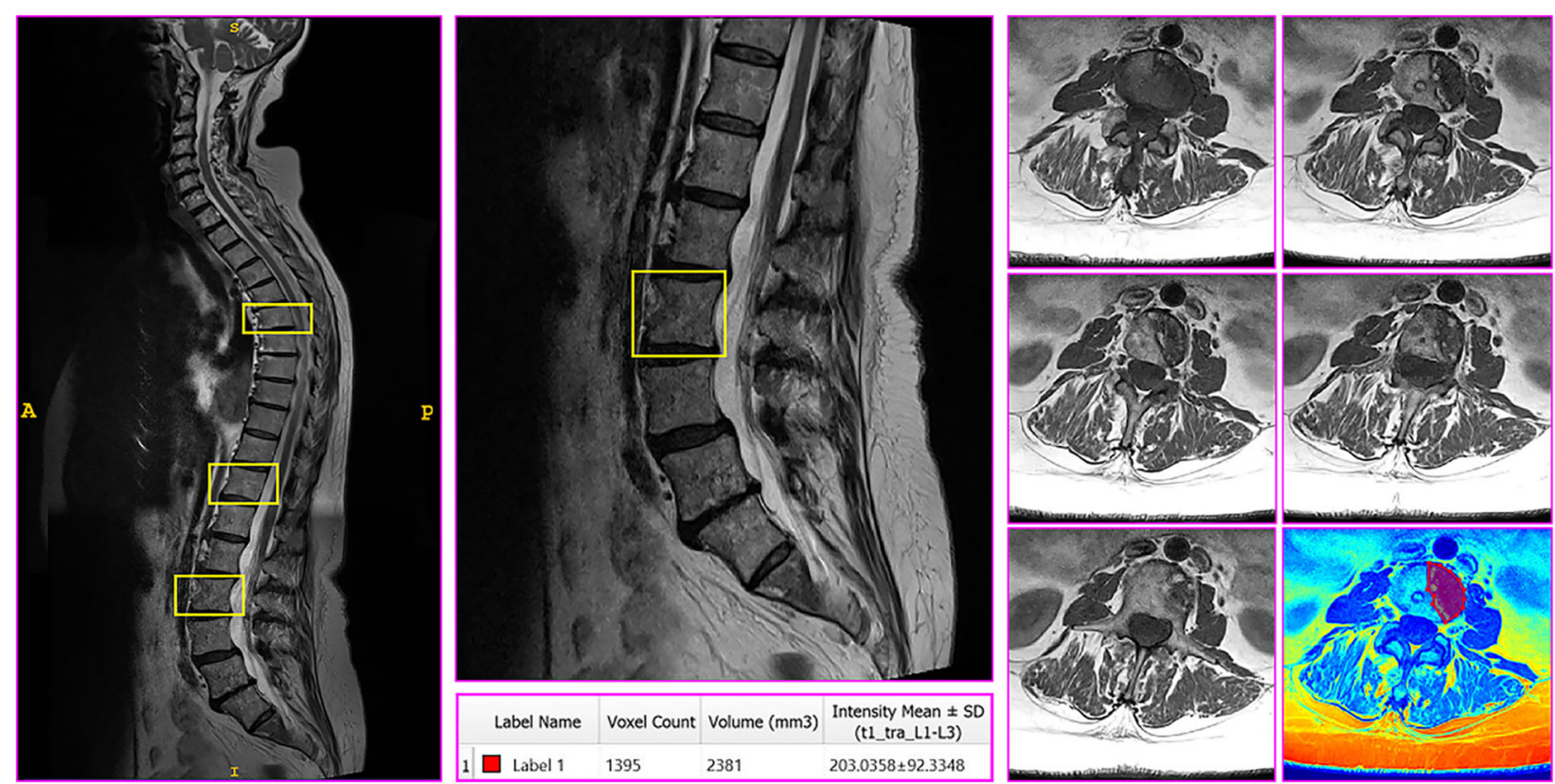

Fig. 2 Example of magnetic resonance imaging (MRI) image acquisition. Left: cervical, thoracic and lumbar scout views stitched together with three osteolytic lesions identified at T5, T11 and L2. Top, middle: lumbar scout view at higher resolution with the L2 vertebra outlined. Bottom, middle: example data outputs provided by regional analysis. Right: slice by slice, cephalad to caudal, transverse view at each level of the L2 lesion, with an example colour map and tumoural analysis of one slice in isolation

and $66 \%$ slices) will be measured and analysed in accordance with Hart and colleagues [87, 88]. Muscle cross-sectional area (Mu.Ar) will also be quantified.

Adiposity Whole-body, segmental and central subcutaneous adipose tissue (fat mass), central visceral adipose tissue (VAT; area, mass and volume) and android-to-gynoid ratio will be measured using DXA. Whole-body and appendicular segmentations will be generated in accordance with Hart and Colleagues [85]. Fat area (Fa.Ar) and muscle density (Mu.Den) of the thigh and shank will be measured using pQCT [87, 88], as an indication of subcutaneous and intramuscular fat infiltration, respectively.

Objective measures of physical function Muscle strength, aerobic capacity and physical function will be assessed. Muscle strength will be measured using the one repetition maximum (1RM) test for the leg extension exercise. This exercise was chosen as it can be safely performed by all patients included in this study. The $400 \mathrm{~m}$ walk test and Timed Up and Go test will be used as measures for aerobic capacity and physical function, respectively. In addition, patients will also undergo a comprehensive balance test (NeuroCom Smart Balance, Natus Medical Inc., USA).
Quality of life, anxiety, distress, insomnia and physical activity Health-related quality of life outcomes for general health, pain, vitality, social functioning, emotional role and mental health will be measured using the Short Form 36 (SF-36, IQOLA) survey. In addition, the European Organisation for Research and Treatment of Cancer (EORTC) Quality of Life Questionnaire, Module 3 (QLQ-30) (cancer) and EORTC Breast Cancer, Module 23 (BR-23) surveys will also be provided to measure cancer-specific indices of quality of life. The FACIT Bone Pain (FACIT-BP) questionnaire will be used to examine bone pain, and the Brief Symptom Inventory (BSI-18) will be used to assess psychological distress for the anxiety, depression, somatisation and global distress severity domains. The Insomnia Severity Index (ISI) will be used to measure sleep quality disturbance, and the Godin Leisure-Time Exercise questionnaire will be applied to examine self-reported physical activity levels.

\section{Exercise programme}

Participants assigned to the exercise arm will be required to participate in a modular, multi-modal exercise programme (M3EP), which includes spinal isometric training (SIT) for 12 weeks. The combined M3EP-SIT programme requires participants to attend three clinic-based exercise sessions each week spanning 60 min in duration (including warm up and cool down), supervised by an accredited exercise physiologist (AEP; 
Exercise and Sport Science Australia). Participants will also be asked to perform the SIT portion of the programme during two additional home-based exercise sessions each week spanning $15 \mathrm{~min}$ in duration. During combined M3EP-SIT sessions, spinal isometric training will be provided first, followed by the modular multi-modal exercise programme (Table 3 ).

The M3EP component of the programme will comprise resistance, aerobic and flexibility exercises in accordance with Galvão and colleagues [48, 51, 55-58]. This M3EP component is designed to minimise loads on affected skeletal sites throughout the body. Exercise prescriptions for all activities will be modified based on the location and extent of bone metastases (Table 4). Resistance exercise will be set using repetition maximums (RM). Participants will be asked to perform six different resistance exercises using major muscle groups, subject to the location and extent of bone metastases, at 10-12 RM for three sets per exercise to achieve moderate intensity and volume. Aerobic exercise will be set using age-predicted heart rate maximum (HRmax). Participants will engage in cardiovascular exercise using various modes including treadmill, cycling and rowing ergometers, performed at $60-85 \%$ HRmax for $20-30$ min using heart rate monitors (Polar Electro Oy, Finland). Flexibility exercise will involve static stretching of muscles at all joints considered important for function, and for all muscles engaged during the session. All stretches will involve $2-4$ sets per muscle group with a 30-60 s hold per set.

The SIT component of the programme will comprise exercises that isometrically load deep spinal muscles as well as the larger superficial trunk musculature. These will be performed five times per week. Three sessions will be supervised by an AEP with the M3EP component at an exercise clinic, with an additional two sessions self-managed by the participant. This SIT component is designed to directly target and stimulate spinal lesion site(s) through muscular contraction, thus isometric exercises have been designed to activate the full spinal column due to the commonality of lesions in cervical, thoracic and lumbar regions, the feasibility of which has been demonstrated [59]. The SIT programme will require the participants to perform five exercises in whole and partial weight-supported prone and supine positions on the floor, whilst maintaining a neutral spine position (isometrically) during gentle and dynamic accessory movements. If floor exercises are contraindicated for the patient due to physical restrictions, alternate seated and standing isometric exercises will be provided. All patients will be initially provided with familiarisation of breathing technique, trunk stabilisation and hip control. Basic spinal isometric exercises will first be used to ensure safe and correct technique prior to progressing to intermediate or more challenging exercises, which include less stability or dynamic accessory movements [89]. Isometric progression of patients from beginner to advanced exercises will be individually determined on the basis of their physical capabilities and known contraindications. An assortment of spinal isometric exercises canvassing beginner to advanced and floor to standing are described in Additional files 1 and 2, respectively, with photographic demonstration of prone and supine exercises in Additional file 3.

\section{Statistical analysis}

Data will be analysed using SPSS (IBM Corporation; Chicago, IL, USA). Normality of distribution of continuous variables will be determined by Shapiro-Wilk test and visual inspection of the data. Analyses will include standard descriptive characteristics, the $t$ test and two-way (group $\times$ time) repeated measures analysis of variance (ANOVA) (or analysis of covariance as appropriate) to examine differences between groups over time. Any data that are not normally distributed will be log-transformed or non-parametric tests will be used. The Pearson chi-square test will be used to analyse categorical variables. An alpha level of $p \leq 0.05$ will be applied to establish statistical significance. Effect sizes will also be calculated in accordance with Hopkins [90]: $d \geq$ 0.2 is small; $d \geq 0.6$ is moderate; $d \geq 1.2$ is large; $d \geq 2.0$ is very large. Incomplete data and missing values will be

Table 3 Weekly distribution of testing, M3EP and SIT exercise sessions across the exercise intervention

\begin{tabular}{|c|c|c|c|c|c|c|c|}
\hline & Monday & Tuesday & Wednesday & Thursday & Friday & Saturday & $\overline{\text { Sunday }}$ \\
\hline Week 0 & \multicolumn{7}{|c|}{ Baseline testing } \\
\hline \multirow[t]{2}{*}{ Week 1 to Week 2} & SIT & - & SIT & - & SIT & REST & REST \\
\hline & \multicolumn{2}{|l|}{ M3EP } & \multicolumn{2}{|l|}{ M3EP } & \multicolumn{3}{|l|}{ M3EP } \\
\hline \multirow[t]{2}{*}{ Week 3 to Week 12} & SIT & SIT & SIT & SIT & SIT & REST & REST \\
\hline & \multicolumn{2}{|l|}{ M3EP } & \multicolumn{2}{|l|}{ M3EP } & \multicolumn{3}{|l|}{ M3EP } \\
\hline Week 13 & \multicolumn{7}{|c|}{ Post-Intervention Testing } \\
\hline
\end{tabular}

Clinic exercise sessions occur on Monday, Wednesday and Friday; home isometric exercise sessions occur on Tuesday and Thursday. Spinal isometric exercises are provided at the start of all clinic exercise sessions (following a general warm up). Home-based SIT starts from week 3 onwards to enable appropriate familiarisation and training during the first 2 weeks of the programme 
Table 4 Modular multi-modal exercise programme for patients with bone metastases $[48,51,56,57]$

\begin{tabular}{|c|c|c|c|c|c|c|}
\hline \multirow[t]{2}{*}{ Metastasis site } & \multicolumn{3}{|c|}{ Resistance } & \multicolumn{2}{|c|}{ Aerobic } & \multirow{2}{*}{$\begin{array}{l}\text { Flexibility } \\
\text { Static }\end{array}$} \\
\hline & Upper & Trunk & Lower & WB & NWB & \\
\hline Pelvis & $\sqrt{ }$ & $\sqrt{ }$ & $\sqrt{* *}$ & & $\sqrt{ }$ & $\sqrt{ }$ \\
\hline Lumbar spine & $\sqrt{ }$ & & $\sqrt{ }$ & & $\sqrt{ }$ & $\sqrt{* * *}$ \\
\hline Thoracic spine/ribs & $\sqrt{ }^{*}$ & & $\sqrt{ }$ & $\sqrt{ }$ & $\sqrt{ }$ & $\sqrt{* * *}$ \\
\hline Proximal femur & $\sqrt{ }$ & $\sqrt{ }$ & $\sqrt{ } * *$ & & $\sqrt{ }$ & $\sqrt{ }$ \\
\hline All regions & $\sqrt{ }^{*}$ & & $\sqrt{ } * *$ & & $\sqrt{ }$ & $\sqrt{* * *}$ \\
\hline
\end{tabular}

Abbreviations: WB weight bearing (e.g. walking), NWB non-weight bearing (e.g. cycling)

$\sqrt{ }$ represents target exercise region

*Exclusion of shoulder flexion/extension/abduction/adduction - inclusion of elbow flexion/extension

**Exclusion of hip extension/flexion - inclusion of knee extension/flexion

***Exclusion of spine/flexion/extension/rotation

primarily managed using an intention-to-treat approach [91] with multiple imputation, specifically using maximum likelihood imputation of missing values. To ensure the robustness of our findings, a secondary sensitivity analysis [92, 93] will be conducted using a complete-cases approach.

\section{Dissemination plan}

Demonstrating the feasibility and safety of delivering targeted exercise (controlled mechanical loads) to skeletal sites with osteolytic lesions in patients with advanced cancer will lead to potential changes in clinical practice. Accordingly, if proven to be safe and feasible, the outcomes of this pilot study will form the basis of future phase II and III clinical trials to establish efficacy; will be published in high-impact peer-reviewed journals; will be presented at national and international conferences or research meetings and will be delivered to the community, consumer-led forums, local hospital departments and university seminars. Evidence from this pilot study may contribute to the renewal of current clinical exercise oncology guidelines for patients with cancer, specifically those in the advanced stages with a high disease burden, within national and international exercise and oncology associations.

Last, the National Breast Cancer Foundation is a charitable organisation dedicated to improving patient outcomes for women and men with breast cancer. As the funder of this pilot study, the National Breast Cancer Foundation will assist with disseminating study outcomes through their extensive clinical, academic and consumer networks nationally. Similarly, the Cancer Council of Western Australia is the premier cancer charity in Western Australia, with wide-reaching connections to clinicians, academics, cancer survivors and their families, and will also assist in disseminating study outcomes through their state-wide networks.

\section{Patient and public involvement}

The Exercise Medicine Research Institute engages consumer representatives (patients with cancer and their families) throughout the conceptual design and development of its research programme to ensure all research questions directly address the needs of patients (in this case, patients with advanced breast cancer), including the engagement of prospective trial participants in a respectful, ethical and impactful way. During the development of this study protocol, authors NHH and RUN presented at national and state breast cancer meetings to patients and clinicians and sought feedback to confirm and optimise the study design. The National Breast Cancer Foundation (the funder of the study), and other cancer charities and associations (such as Breast Cancer Network Australia, Breast Cancer Care Western Australia and the Cancer Council of Western Australia) will assist in the dissemination of findings to their cancer support groups and the general public. Study participants will receive their individual results at the conclusion of their involvement and overall study results at the conclusion of the study.

The research team of this study protocol includes a surgical oncologist (CS), radiation oncologists (NAS, $\mathrm{RC}$ ) and medical oncologists (KTF, DT, HM, TC, ADR) who work with the target population on a daily basis, from which patient priorities, experiences and preferences gleaned from this engagement helped inform the development of the research questions and outcome measures. Last, the broader research team (NHH, RUN, DAG, DRT, NAS) have conducted research studies in exercise oncology involving a large number of patients over the course of the past 15 years, where participants have provided feedback to investigators to help design feasible, safe and effective exercise oncology clinical trials. This sizeable interaction across the clinical and community landscape contributed substantially to the design of this project.

\section{Discussion}

Complications arising from bone metastases present a major clinical issue for patients and clinicians alike [18], with bone metastases evident in over $80 \%$ of metastatic breast carcinoma (advanced breast cancer) cases. Currently, it is a treatable, yet incurable stage of disease, thus strategies that delay disease progression and extend survival without an adverse impact on quality of life or excessive clinical risk are highly sought after. Exercise medicine is an emerging field in oncology (i.e. exercise oncology), known for its neo-adjuvant and adjuvant role for symptom control, reduction of treatment toxicity and ability to improve the tolerance of and recovery from intensive cancer treatment regimens [48, 52, 65, 94-103]. Recent insights are beginning to illustrate the 
synergistic (assistive) and targeted (independent) role of exercise medicine in patients with cancer throughout the disease trajectory to assist with delaying disease progression and plausibly extending overall survival, largely through preclinical studies ([13, 14, 47-51, 70-74, 83, 104-118]) or epidemiological associations [119-134]. Most promisingly, exercise seems to be able to favourably modulate tumour biology towards improving cancer control, including skeletal orthotopic models, highlighting a key candidate intervention for human, patient-focused studies to target and pursue [14, 51, 135].

Exercise medicine may positively alter tumour biology through numerous mechanical and non-mechanical mechanisms targeting local, neighbouring and systemic pathways in response to various modes and dosages of activity [70-74, 105, 110, 112, 113, 136]. Specifically, exercise regulates endocrine-paracrine activity, systemic immune function (pro-inflammatory and anti-inflammatory activity), blood glucose and blood cholesterol levels, insulin response and body composition [97-101, 106, 116, 137, 138]. Exercise can also epigenetically modulate tumour vasculature (morphology and permeability), tumour cell proliferation (growth and distribution), telomeres (length and enzyme activity), platelet functions (cloaking and adhesion) and oxidative stress capacity $[49,50,113,139-144]$. Whilst exercise concurrently acts across many of these regulatory and modulatory pathways, the targeted suppression of tumour formation, growth and invasion through mechanically driven epigenetic alterations, and muscle driven endocrine-paracrine activity is of particular interest. Indeed, biological alterations from biomechanical stimuli and biochemical responses (an emerging field known as "mechanomics", applied to exercise oncology) [8, 12, 118, 145, 146] presents clinicians and allied health practitioners (such as clinical exercise physiologists) with a unique opportunity to suppress the growth and spread of metastatic breast carcinoma in bone through targeted exercise interventions.

Compelling new insights from metastatic orthotopic animal models demonstrate the ability of mechanical stimulation (i.e. repeated bouts of external compression) to interfere with tumour-driven remodelling in skeletal tissue containing human breast cancer cells [13, 41]. Exercise is a dose-dependent mechanical stimulant (with evidence of dose-response) that can be safely prescribed to patients with advanced prostate cancer and sclerotic metastases [14, 48, 51, 55, 57, 58, 106]. It is of equal interest to explore whether this can also be achieved in patients with advanced breast cancer with osteolytic metastases, who experience skeletal fragility at much faster rates than their counterparts with sclerotic metastases. Furthermore, it is of interest to explore whether skeletal integrity and tumoural suppression are prevalent in humans, as preclinical studies do not always translate to the human condition [61-63]. Indeed, it is not yet known whether disease-affected bone sites adapt to mechanical stimuli to the same order of magnitude or in the same morphological manner as unaffected healthy bone sites; nor is it clear how muscle surrounding lesions may adapt given the catabolic tumour microenvironment.

Accordingly, this study is our evaluation of the feasibility, safety and preliminary efficacy of a modular, multi-modal exercise programme, coupled with spinal isometric training, to provide a non-invasive, low-cost, innovative and scalable therapy in the management of advanced breast cancer. Examination of the modulatory potential of direct and targeted mechanical loading of osteolytic spinal bone metastases will also be conducted by quantifying tumour morphology and systemic activity of metastatic biomarkers (HIF- $1 \alpha$, local hypoxia; TGF- $\beta$, transformation growth-like factor), whilst also exploring whether targeted exercise can reduce bone pain, preserve neighbouring skeletal mass and structure (i.e. unaffected vertebrae above and below affected lesion sites) and reduce or avoid exacerbation of bone pain. Additionally, this study will also examine the multifaceted and broader effects of exercise participation by patients with advanced breast cancer on muscle and bone health (mass and strength), adiposity (subcutaneous and visceral), physical fitness and function and psychosocial health (focusing on quality of life).

Outcomes of this study will inform future research into sclerotic, osteolytic or mixed lesions across solid and haematological malignancies (such as multiple myeloma), particularly in patients with cancer and extensive or widespread bone metastases and high disease burdens who would otherwise be contraindicated for exercise. Optimistically, the generalisability of this exercise programme across models seems achievable, given it is supervised, individualised and tailored to each patient's unique condition, and thus auto-regulated accordingly [48, 51]. The mechanistic insights of this study may also inform the development of effective pharmaceutical or medical treatments with avenues to target bone metastases. Given the preliminary efficacy (phase 1) nature of this pilot study, the results will be used to pursue larger phase II and III clinical trials to determine the efficacy of the programme in tumour suppression or regression in patients with osteolytic bone metastases secondary to breast cancer, and to develop an exercise program that can inevitably and immediately be delivered in clinical and community settings by accredited or certified clinical exercise physiologists.

\section{Additional files}

Additional file 1: Floor-based, spinal isometric exercise library for patients with prostate cancer and spinal bone metastases, to cater for varying physical capabilities and training progression rates. (PDF 554 kb) 
Additional file 2: Seated and standing, spinal isometric exercise library for patients with prostate cancer and spinal bone metastases, to cater for patients unable to perform floor-based exercises. (PDF $511 \mathrm{~kb}$ )

Additional file 3: Photographic examples of prone (left) and supine (right) floor-based spinal isometric exercises, illustrating the start position and final hold positions of each labelled exercise to assist exercise physiologists and patients with cancer. The patient shown has signed a media release consent form. (PDF $923 \mathrm{~kb}$ )

Additional file 4: SPIRIT 2013 Checklist: Recommended items to address in a clinical trial protocol and related documents. (DOCX $51 \mathrm{~kb}$ )

\section{Abbreviations}

aBMC: Areal bone mineral content; aBMD: Areal bone mineral density; ACTRN: Australian Clinical Trials Registry Number; ADR: Andrew D Redfern; AEP: Accredited exercise physiologist; ALP: Alkaline phosphatase; ANOVA: Analysis of variance; ANZCTR: Australia and New Zealand Clinical Trials Registry; BA: Bone area; BMI: Body mass index; BP: Bone pain; BR23: Breast Cancer, Module 23; BSI-18: Brief Symptom Inventory, Module 18; CRP: C-reactive protein; CS: Christobel Saunders; Ct.Th: Cortical thickness; Ct.vBMD: Cortical volumetric bone mineral density; CTCAE: Common terminology criteria for adverse events; DAG: Daniel A Galvão; DRT: Dennis R Taaffe; DT: Daphne Tsoi; DXA: Dual-energy x-ray absorptiometry; ECOG: European Cooperative Oncology Group; ECU: Edith Cowan University; Fa.Ar: Fat area; FACIT: Functional Assessment of Chronic Illness Therapy; FL.Ab: Fracture load, absolute; FL.Rel: Fracture Load, Relative; HIF-1a: Hypoxiainducible factor, one alpha.; HM: Hilary Martin; HR+: Hormone receptor positive.; HR-: Hormone receptor negative; HREC: Human Research Ethics Committee; HRmax: Heart rate maximum; ICMJE: International Committee of Medical Journal Editors; ID: Identifier; IQOLA: International Quality of Life Assessment; ISI: Insomnia Severity Index; KTF: Kynan T Feeney; M3EP: Modular, multimodal exercise program; Ma.Ar: Marrow area; Ma.vBMD: Marrow volumetric bone mineral density; MRI: Magnetic resonance imaging; Mu.Ar: Muscle area; Mu.Den: Muscle density; NAS: Nigel A Spry; NHH: Nicolas H Hart; NTx: Amino-terminal collagen type-l telopeptide; P1NP: Amino-terminal propeptide of type 1 procollagen; PQCT: Peripheral quantitative computed tomography; QLQ-30: Quality of Life Questionnaire, Module 3; RC: Raphael Chee; RM: Repetition maximum; RUN: Robert U Newton; SCGOPHG: Sir Charles Gairdner Osborne Park Health Group; SF36: Short Form, Module 36; SIT: Spinal isometric training; SJOG: St John of God Hospital; SKC: Suzanne K Chambers; SPSS: Statistical Package for the Social Sciences; SSIPOL: Stress-Strain Index Polar; Tb.Ar: Trabecular area; Tb.vBMD: Trabecular volumetric bone mineral density; TC: Tim Clay; TGF$\beta$ : Transformation growth-like factor, beta.; Tt.Ar: Total area; Tt.vBMD: Total volumetric bone mineral density; VAS: Visual analogue scale; VAT: Visceral adipose tissue

\section{Acknowledgements}

The authors would like to thank the National Breast Cancer Foundation and their generous donors for support of our research programme, as it is through these philanthropic donations that our research trial has been launched. The authors would also like to thank Dr Kirk Feindel (Centre for Microscopy, Characterisation and Analysis; University of Western Australia), Mr Joey Chau (InSight Clinical Imaging), Mr Kyle Smith and Ms Audrey Cox (Vario Health Clinic; Edith Cowan University), Miss Thea Richardson (Australian Prostate Cancer Research Centre), Mrs Claire Mason, Miss Olivia Pisconeri and Miss Cailyn Rogers (Exercise Medicine Research Institute; Edith Cowan University) for their contribution. Most importantly, the authors would like to thank Mrs Annie McKinnon (Breast Cancer Consumer Representative) for her dedicated and passionate contribution to breast cancer research and this study protocol, and Mrs Margaret Wilson for her excellent demonstration of selected floor-based isometric exercises in Additional file 3 .

\section{Funding}

This project is funded by the National Breast Cancer Foundation of Australia. The National Breast Cancer Foundation is national charity organisation committed to improving health outcomes for women and men living with breast cancer. NHH is supported by a Cancer Council of Western Australia Postdoctoral Research Fellowship. SKC is supported by an Australian Research Council Professorial Future Fellowship. DRT is supported by a
Professorial Research Fellowship at Edith Cowan University. ADR is supported by a Cancer Council of Western Australia Clinician Research Fellowship.

\section{Availability of data and materials}

All outcome data (primary and secondary) will be published in peerreviewed clinical and academic journal articles, and will be presented at medical, clinical, academic or community conferences, seminars and/or meetings on an ongoing basis. This study adhered to the SPIRIT checklist, available via Additional file 4. Unpublished data, if any, can be requested at the conclusion of the trial through a written request to the Exercise Medicine Research Institute: emri@ecu.edu.au

\section{Authors' contributions}

$\mathrm{NHH}, \mathrm{DAG}, \mathrm{RUN}, \mathrm{CS}, \mathrm{NAS}$ and DT developed the study concept and protocols and initiated the project. DRT, SKC, KTF, RC, TC, ADR and HM assisted in further development of the protocol. NHH, DAG, RUN, DRT and SKC drafted the manuscript. CS, NAS, DT, RC, TC, ADR, HM and KTF are providing access to patients and have provided clinical input into the study. $\mathrm{NHH}, \mathrm{DAG}$ and RUN are currently implementing the protocol and overseeing collection of data. All authors contributed and approved the final manuscript in accordance with the International Committee of Medical Journal Editors (ICMJE) recommendations.

\section{Ethics approval and consent to participate}

Ethics approval was obtained through Edith Cowan University's Human Research Ethics Committee (ID 14266 NEWTON), St John of God Hospital Ethics Committee (ID 969), and Sir Charles Gairdner and Osborne Park Health Group Ethics Committee (ID 2016-118), covering recruiting hospitals sites within the public health system (North Metropolitan Health Service, namely Sir Charles Gairdner Hospital and South Metropolitan Health Service, namely Fiona Stanley Hospital) and private health system (St John of God Hospitals in Subiaco and Murdoch). All patients involved in this study are required to give written informed consent in order to be enrolled for participation.

\section{Competing interests}

ADR is a current member of the Research Advisory Committee of the National Breast Cancer Foundation. The remaining authors have no competing interests to declare.

\section{Publisher's Note}

Springer Nature remains neutral with regard to jurisdictional claims in published maps and institutional affiliations.

\section{Author details}

${ }^{1}$ Exercise Medicine Research Institute, Edith Cowan University, 270 Joondalup Drive, Joondalup, Perth, Western Australia 6027, Australia. ${ }^{2}$ Institute for Health Research, University of Notre Dame Australia, Perth, WA, Australia. ${ }^{3}$ School of Medical and Health Sciences, Edith Cowan University, Perth, WA, Australia. ${ }^{4}$ St John of God Hospital, Perth, WA, Australia. ${ }^{5}$ Royal Perth Hospital, Perth, WA, Australia. ${ }^{6}$ School of Medicine, University of Western Australia, Perth, WA, Australia. 'School of Medicine, University of Notre Dame Australia, Perth, WA, Australia. ${ }^{8}$ Genesis CancerCare, Perth, WA, Australia. ${ }^{9}$ Fiona Stanley Hospital, Perth, WA, Australia. ${ }^{10}$ School of Human Movement and Nutrition Sciences, University of Queensland, Brisbane, QLD, Australia.

\section{Received: 24 August 2018 Accepted: 30 November 2018} Published online: 20 December 2018

\section{References}

1. Kozlow W, Guise TA. Breast cancer metastasis to bone: mechanisms of osteolysis and implications for therapy. J Mammary Gland Biol Neoplasia. 2005;10(2):169-80.

2. Zacharia B, Subramaniam D, Joy J. Skeletal metastasis - an epidemiological study. Ind J Surg Oncol. 2018;9(1):46-51.

3. Redig AJ, McAllister SS. Breast cancer as a systemic disease: a view of metastasis. J Intern Med. 2013;274(2):113-26.

4. Weigelt $B$, Peterse $J L$, Van't Veer $\sqcup$. Breast cancer metastasis: markers and models. Nat Rev Cancer. 2005;5(8):591-602.

5. Barney LE, Jansen LE, Polio SR, Galarza S, Lynch ME, Peyton SR. The predictive link between matrix and metastasis. Curr Opin Chem Eng. 2016;11:85-93. 
6. Wang N, Reeves KJ, Brown HK, Fowles AC, Docherty FE, Ottewell PD, et al. The frequency of osteolytic bone metastasis is determined by conditions of the soil, not the number of seeds; evidence from in vivo models of breast and prostate cancer. J Exp Clin Cancer Res. 2015;34(1):124.

7. Macedo F, Ladeira K, Pinho F, Saraiva N, Bonito N, Pinto L, et al. Bone metastases: an overview. Oncol Rev. 2017;11(1):321.

8. Lynch ME, Fischbach C. Biomechanical forces in the skeleton and their relevance to bone metastasis: Biology and engineering considerations. Adv Drug Deliv Rev. 2014;79-80:119-34.

9. Høilund-Carlsen PF, Hess S, Werner TJ, Alavi A. Cancer metastasizes to the bone marrow and not to the bone: time for a paradigm shift! Eur J Nucl Med Mol Imaging. 2018;45(6):893-7.

10. Hata K, Yoneda T. Bone metastases of breast cancer. Clin Calcium. 2014; 24(8):1177-84.

11. Cawthorn WP, Scheller EL. Bone marrow adipose tissue: formation, function, and impact on health and disease. Front Endocrinol. 2017;8:112.

12. Hart NH, Nimphius S, Rantalainen T, Ireland A, Siafarikas A, Newton R. Mechanical basis of bone strength: influence of bone material, bone structure and muscle action. J Musculoskelet Nueronal Interact. 2017;17(3):114

13. Lynch ME, Brooks D, Mohanan S, Lee MJ, Polamraju P, Dent K, et al. In vivo tibial compression decreases osteolysis and tumor formation in a human metastatic breast cancer model. J Bone Miner Res. 2013;28(11): 2357-67.

14. Hart NH, Newton RU, Spry NA, Taaffe DR, Chambers SK, Feeney KT, et al. Can exercise suppress tumour growth in advanced prostate cancer patients with sclerotic bone metastases? A randomised, controlled study protocol examining feasibility, safety and efficacy. BMJ Open. 2017;7(5):e014458.

15. Rizzoli R, Body J-J, Brandi M-L, Cannata-Andia J, Chappard D, El Maghraoui A, et al. Cancer-associated bone disease. Osteoporos Int. 2013;24(12):2929-53.

16. Sanna-Maria K, Mundy GR. Mechanisms of osteolytic bone metastases in breast carcinoma. Cancer. 2003;97(3):834-9.

17. Suva LJ, Washam C, Nicholas RW, Griffin RJ. Bone metastasis: mechanisms and therapeutic opportunities. Nat Rev Endocrinol. 2011;7(4):208-18.

18. Coleman RE. Clinical features of metastatic bone disease and risk of skeletal morbidity. Clin Cancer Res. 2006;12(20):6243s-9s.

19. Roodman GD. Mechanisms of bone metastasis. N Engl J Med. 2004;350(16): 1655-64.

20. Holen I. The bone microenvironment - multiple players involved in cancer progression. J Bone Oncol. 2016;5(3):87-9.

21. Patel SA, Dave MA, Murthy RG, Helmy KY, Rameshwar P. Metastatic breast cancer cells in the bone marrow microenvironment: novel insights into oncoprotection. Oncol Rev. 2011;5(2):93-102.

22. Roato I, Ferracini R. Cancer stem cells, bone and tumor microenvironment: key players in bone metastases. Cancers. 2018;10(2):56.

23. Secomb TW, Alberding JP, Hsu R, Dewhirst MW, Pries AR. Angiogenesis: an adaptive dynamic biological patterning problem. PLoS Comput Biol. 2013; 9(3):e1002983.

24. Banerjee S, Pillai M, Knapp F. Lutetium-177 therapeutic radiopharmaceuticals: linking chemistry, radiochemistry, and practical applications. Chem Rev. 2015;115(8):2934-74.

25. Cardoso F, Costa A, Senkus E, Aapro M, André F, Barrios C, et al. 3rd ESOESMO international consensus guidelines for advanced breast cancer ( $A B C$ 3). Ann Oncol. 2017;28(1):16-33.

26. Cheal S, Fung E, Xu H, Guo H-f, Patel M, Bell M, et al. Comparative efficacy and toxicity of 177Lu-vs 90Y-theranostic anti-HER2/anti-DOTA (metal) pretargeted radioimmunotherapy (anti-HER2 DOTA-PRIT) of HER2-expressing breast cancer xenografts with curative intent. J Nuclear Med. 2017;58(Suppl 1):54.

27. Denkert C, Liedtke C, Tutt A, von Minckwitz G. Molecular alterations in triple-negative breast cancer - the road to new treatment strategies. Lancet. 2017;389(10087):2430-42.

28. Giordano SH, Temin S, Kirshner JJ, Chandarlapaty S, Crews JR, Davidson NE, et al. Systemic therapy for patients with advanced human epidermal growth factor receptor 2-positive breast cancer: American Society of Clinical Oncology clinical practice guideline. J Clin Oncol. 2014;32(19):2078-99.

29. Loftus LS, Edwards-Bennett S, Sokol GH. Systemic therapy for bone metastases. Cancer Control. 2012;19(2):145-53.

30. Lutz S, Balboni T, Jones J, Lo S, Petit J, Rich SE, et al. Palliative radiation therapy for bone metastases: update of an ASTRO evidence-based guideline. Pract Radiat Oncol. 2017;7(1):4-12.

31. Sledge GW Jr, Toi M, Neven P, Sohn J, Inoue K, Pivot $X$, et al. MONARCH 2: abemaciclib in combination with fulvestrant in women with HR+/HER2- advanced breast cancer who had progressed while receiving endocrine therapy. J Clin Oncol. 2017;35(25):2875-84.

32. Van Poznak CH, Temin S, Yee GC, Janjan NA, Barlow WE, Biermann JS, et al. American Society of Clinical Oncology executive summary of the clinical practice guideline update on the role of bone-modifying agents in metastatic breast cancer. J Clin Oncol. 2011;29(9):1221-7.

33. O'Carrigan B, Wong MH, Willson ML, Stockler MR, Pavlakis N, Goodwin A. Bisphosphonates and other bone agents for breast cancer. Cochrane Database Syst Rev. 2017;10:CD003474.

34. Stopeck AT, Lipton A, Body J-J, Steger GG, Tonkin K, De Boer RH, et al. Denosumab compared with zoledronic acid for the treatment of bone metastases in patients with advanced breast cancer: a randomized, doubleblind study. J Clin Oncol. 2010;28(35):5132-9.

35. Diab DL, Watts NB. Bisphosphonate drug holiday: who, when and how long. London: SAGE Publications Sage UK; 2013.

36. Silverman S, Adachi J, Dennison E. Bisphosphonate drug holidays: we reap what we sow. Osteoporos Int. 2016;27(3):849-52.

37. Vannucci L, Brandi ML. Pharmacological management of osteoporosis-when to treat and when to stop. Expert Rev Clin Pharmacol. 2016;9(10):1315-22

38. Ireland A, Rittweger J, Degens $H$. The influence of muscular action on bone strength via exercise. Clin Rev Bone Mineral Metab. 2014;12(2):93-102.

39. Nikander R, Kannus P, Rantalainen T, Uusi-Rasi K, Heinonen A, Sievänen H. Cross-sectional geometry of weight-bearing tibia in female athletes subjected to different exercise loadings. Osteoporos Int. 2010;21(10):1687-94.

40. Liu B, Han S, Hedrick BP, Modarres-Sadeghi Y, Lynch ME. Perfusion applied to a $3 \mathrm{D}$ model of bone metastasis results in uniformly dispersed mechanical stimuli. Biotechnol Bioeng. 2018;115(4):1076-85.

41. Lynch ME, Chiou AE, Lee MJ, Marcott SC, Polamraju PV, Lee Y, et al. Threedimensional mechanical loading modulates the osteogenic response of mesenchymal stem cells to tumor-derived soluble signals. Tissue Eng A. 2016;22(15-16):1006-15.

42. Cardozo CP, Graham ZA. Muscle-bone interactions: movement in the field of mechano-humoral coupling of muscle and bone. Ann N Y Acad Sci. 2017;1402(1):10-7.

43. Karsenty G, Mera P. Molecular bases of the crosstalk between bone and muscle. Bone. 2017. https://doi.org/10.1016/j.bone.2017.04.006.

44. Regan JN, Trivedi T, Guise TA, Waning DL. The role of TGF $\beta$ in bone-muscle crosstalk. Curr Osteoporosis Rep. 2017;15(1):18-23.

45. Waning DL, Mohammad KS, Reiken S, Xie W, Andersson DC, John S, et al. Excess TGF- $\beta$ mediates muscle weakness associated with bone metastases in mice. Nat Med. 2015;21(11):1262-71.

46. Hoffmann C, Weigert C. Skeletal muscle as an endocrine organ: the role of myokines in exercise adaptations. Cold Spring Harbor Perspect Med. 2017; 7(11):a029793.

47. Hojman P, Gehl J, Christensen JF, Pedersen BK. Molecular mechanisms linking exercise to cancer prevention and treatment. Cell Metab. 2018;27(1):10-21.

48. Hart NH, Galvão DA, Newton RU. Exercise medicine for advanced prostate cancer. Curr Opin Support Palliat Care. 2017;11(3):247-57.

49. Ruiz-Casado A, Martín-Ruiz A, Pérez LM, Provencio M, Fiuza-Luces C, Lucia A Exercise and the hallmarks of cancer. Trends Cancer. 2017;3(6):423-41.

50. Galvão DA, Taaffe DR, Spry N, Gardiner RA, Taylor R, Risbridger GP, et al. Enhancing active surveillance of prostate cancer: the potential of exercise medicine. Nat Rev Urol. 2016;13(5):258.

51. Newton RU, Kenfield SA, Hart NH, Chan JM, Courneya KS, Catto J, et al. Intense exercise for survival among men with metastatic castrate-resistant prostate cancer (INTERVAL-GAP4): a multicentre, randomised, controlled phase III study protocol. BMJ Open. 2018;8(5):e022899.

52. Galvao DA, Taaffe DR, Spry N, Joseph D, Newton RU. Combined resistance and aerobic exercise program reverses muscle loss in men undergoing androgen suppression therapy for prostate cancer without bone metastases: a randomized controlled trial. J Clin Oncol. 2010;28(2):340-7.

53. Sheill G, Guinan EM, Peat N, Hussey J. Considerations for exercise prescription in patients with bone metastases: a comprehensive narrative review. PM R. 2018. https://doi.org/10.1016/j.pmrj.2018.02.006.

54. Zopf E, Newton RU, Taaffe DR, Spry N, Cormie P, Joseph D, et al. Associations between aerobic exercise levels and physical and mental health outcomes in men with bone metastatic prostate cancer: a crosssectional investigation. Eur J Cancer Care. 2017;26(6):e12575.

55. Cormie P, Newton RU, Spry N, Joseph D, Taaffe DR, Galvao DA. Safety and efficacy of resistance exercise in prostate cancer patients with bone metastases. Prostate Cancer Prostatic Dis. 2013;16(4):328-35. 
56. Galvão DA, Taaffe DR, Cormie P, Spry N, Chambers SK, Peddle-Mclntyre C, et al. Efficacy and safety of a modular multi-modal exercise program in prostate cancer patients with bone metastases: a randomized controlled trial. BMC Cancer. 2011;11(1):517.

57. Galvao DA, Taaffe DR, Spry N, Cormie P, Joseph D, Chambers SK, et al. Exercise preserves physical function in prostate cancer patients with bone metastases. Med Sci Sports Exerc. 2018;50(3):393.

58. Cormie P, Galvão DA, Spry N, Joseph D, Taaffe DR, Newton RU. Functional benefits are sustained after a program of supervised resistance exercise in cancer patients with bone metastases: longitudinal results of a pilot study. Support Care Cancer. 2014;22(6):1537-48.

59. Rief H, Omlor G, Akbar M, Welzel T, Bruckner T, Rieken S, et al. Feasibility of isometric spinal muscle training in patients with bone metastases under radiation therapy-first results of a randomized pilot trial. BMC Cancer. 2014;14(1):67.

60. Rief H, Petersen LC, Omlor G, Akbar M, Bruckner T, Rieken S, et al. The effect of resistance training during radiotherapy on spinal bone metastases in cancer patients-a randomized trial. Radiother Oncol. 2014;112(1):133-9.

61. Ireland A, Rittweger J. Exercise for osteoporosis: how to navigate between overeagerness and defeatism. J Musculoskelet Neuronal Interact. 2017;17(3):155-61.

62. Mak IW, Evaniew N, Ghert M. Lost in translation: animal models and clinical trials in cancer treatment. Am J Transl Res. 2014;6(2):114-8.

63. Van der Worp HB, Howells DW, Sena ES, Porritt MJ, Rewell S, O'Collins V, et al. Can animal models of disease reliably inform human studies? PLoS Med. 2010;7(3):e1000245.

64. Cormie P, Galvão DA, Spry N, Joseph D, Chee R, Taaffe DR, et al. Can supervised exercise prevent treatment toxicity in patients with prostate cancer initiating androgen-deprivation therapy: a randomised controlled trial. BJU Int. 2015;115(2):256-66.

65. Galvao D, Taaffe D, Spry N, Newton R. Exercise can prevent and even reverse adverse effects of androgen suppression treatment in men with prostate cancer. Prostate Cancer Prostatic Dis. 2007;10(4):340.

66. Galvao DA, Spry N, Denham J, Taaffe DR, Cormie P, Joseph D, et al. A multicentre year-long randomised controlled trial of exercise training targeting physical functioning in men with prostate cancer previously treated with androgen suppression and radiation from TROG 03.04 RADAR. Eur Urol. 2014:65(5):856-64

67. Galvão DA, Spry N, Taaffe DR, Denham J, Joseph D, Lamb DS, et al. A randomized controlled trial of an exercise intervention targeting cardiovascular and metabolic risk factors for prostate cancer patients from the RADAR trial. BMC Cancer. 2009;9(1):419.

68. Newton RU, Taaffe DR, Spry N, Cormie P, Chambers SK, Gardiner RA, et al. Can exercise ameliorate treatment toxicity during the initial phase of testosterone deprivation in prostate cancer patients? Is this more effective than delayed rehabilitation? BMC Cancer. 2012;12(1):432.

69. Kennecke H, Yerushalmi R, Woods R, Cheang MCU, Voduc D, Speers CH, et al. Metastatic behavior of breast cancer subtypes. J Clin Oncol. 2010;28(20): 3271-7

70. Betof AS, Lascola CD, Weitzel D, Landon C, Scarbrough PM, Devi GR, et al. Modulation of murine breast tumor vascularity, hypoxia, and chemotherapeutic response by exercise. JNCl. 2015;107(5):djv040.

71. Jones LW, Antonelli J, Masko EM, Broadwater G, Lascola CD, Fels D, et al. Exercise modulation of the host-tumor interaction in an orthotopic model of murine prostate cancer. J Appl Physiol. 2012;113(2):263-72.

72. Wolff G, Balke JE, Andras IE, Park M, Toborek M. Exercise modulates redoxsensitive small GTPase activity in the brain microvasculature in a model of brain metastasis formation. PLoS One. 2014;9(5):e97033.

73. Jones LW, Fels DR, West M, Allen JD, Broadwater G, Barry WT, et al. Modulation of circulating angiogenic factors and tumor biology by aerobic training in breast cancer patients receiving neoadjuvant chemotherapy. Cancer Prev Res. 2013;6(9):925-37.

74. Glass OK, Inman BA, Broadwater G, Courneya KS, Mackey JR, Goruk S, et al. Effect of aerobic training on the host systemic milieu in patients with solid tumours: an exploratory correlative study. Br J Cancer. 2015;112(5):825.

75. Cook GJ, Azad GK, Goh V. Imaging bone metastases in breast cancer: staging and response assessment. J Nuclear Med. 2016;57(Supplement 1): 27S-33S.

76. Costelloe CM, Rohren EM, Madewell JE, Hamaoka T, Theriault RL, Yu T-K, et al. Imaging bone metastases in breast cancer: techniques and recommendations for diagnosis. Lancet Oncol. 2009;10(6):606-14.

77. Lecouvet F, Talbot JN, Messiou C, Bourguet P, Liu Y, de Souza NM Monitoring the response of bone metastases to treatment with magnetic resonance imaging and nuclear medicine techniques: a review and position statement by the European Organisation for Research and Treatment of Cancer imaging group. Eur J Cancer. 2014;50(15):2519-31.

78. Shah LM, Salzman KL. Imaging of spinal metastatic disease. Int J Surg Oncol. 2011;2011:769753

79. Yushkevich PA, Piven J, Hazlett HC, Smith RG, Ho S, Gee JC, et al. Userguided $3 \mathrm{D}$ active contour segmentation of anatomical structures: significantly improved efficiency and reliability. Neurolmage. 2006;31(3): 1116-28.

80. Dunn LK, Mohammad KS, Fournier PGJ, McKenna CR, Davis HW, Niewolna $M$, et al. Hypoxia and TGF- $\beta$ drive breast cancer bone metastases through parallel signaling pathways in tumor cells and the bone microenvironment. PLoS One. 2009:4(9):e6896.

81. Guise TA, Chirgwin JM. Transforming growth factor-beta in osteolytic breast cancer bone metastases. Clin Orthop Relat Res ${ }^{\oplus}$. 2003;415:S32-S8.

82. Hiraga T, Kizaka-Kondoh S, Hirota K, Hiraoka M, Yoneda T. Hypoxia and hypoxia-inducible factor-1 expression enhance osteolytic bone metastases of breast cancer. Cancer Res. 2007;67(9):4157-63.

83. Semenza GL. The hypoxic tumor microenvironment: a driving force for breast cancer progression. Biochimica et Biophysica Acta (BBA)-Molecular. Cell Res. 2016;1863(3):382-91.

84. Drabsch $Y$, Ten Dijke P. TGF- $\beta$ signalling and its role in cancer progression and metastasis. Cancer Metastasis Rev. 2012;31(3-4):553-68.

85. Hart NH, Nimphius S, Spiteri T, Cochrane JL, Newton RU. Segmental musculoskeletal examinations using dual-energy $\mathrm{x}$-ray absorptiometry (DXA): positioning and analysis considerations. J Sports Sci Med. 2015; 14(3):620.

86. Anon. QDR for Windows XP Reference Manual. Bedford: Hologic Inc.; 2014.

87. Hart NH, Nimphius S, Weber J, Spiteri T, Rantalainen T, Dobbin M, et al. Musculoskeletal asymmetry in football athletes: a product of limb function over time. Med Sci Sports Exerc. 2016;48(7):1379-87.

88. Rantalainen T, Chivers P, Beck BR, Robertson S, Hart NH, Nimphius S, et al. Please don't move-evaluating motion artifact from peripheral quantitative computed tomography scans using textural features. J Clin Densitom. 2018; 21(2):260-8

89. McGill SM. Low back stability: from formal description to issues for performance and rehabilitation. Exerc Sport Sci Rev. 2001;29(1):26-31.

90. Hopkins WG. A scale of magnitudes for effect statistics. A new view of statistics. 2002. Available from: www.sportsci.org/resource/stats/effectmag.html.

91. Gupta SK. Intention-to-treat concept: a review. Perspect Clin Res. 2011;2(3):109.

92. Thabane L, Mbuagbaw L, Zhang S, Samaan Z, Marcucci M, Ye C, et al. A tutorial on sensitivity analyses in clinical trials: the what, why, when and how. BMC Med Res Methodol. 2013;13(1):92.

93. Bell ML, Fiero M, Horton NJ, Hsu C-H. Handling missing data in RCTs; a review of the top medical journals. BMC Med Res Methodol. 2014;14(1):118.

94. Beydoun N, Bucci JA, Chin YS, Spry N, Newton R, Galvão DA. Prospective study of exercise intervention in prostate cancer patients on androgen deprivation therapy. J Med Imaging Radiat Oncol. 2014;58(3):369-76.

95. Galvão DA, Newton RU, Taaffe DR, Spry N. Can exercise ameliorate the increased risk of cardiovascular disease and diabetes associated with ADT? Nat Rev Urol. 2008:5(6):306.

96. Jones LW, Alfano CM. Exercise-oncology research: past, present, and future. Acta Oncol. 2013;52(2):195-215.

97. Jones LW, Habel LA, Weltzien E, Castillo A, Gupta D, Kroenke CH, et al. Exercise and risk of cardiovascular events in women with nonmetastatic breast cancer. J Clin Oncol. 2016;34(23):2743.

98. Kim TH, Chang JS, Kong ID. Effects of exercise training on physical fitness and biomarker levels in breast cancer survivors. J Lifestyle Med. 2017:7(2):55-62

99. Thomas GA, Cartmel B, Harrigan M, Fiellin M, Capozza S, Zhou Y, et al. The effect of exercise on body composition and bone mineral density in breast cancer survivors taking aromatase inhibitors. Obesity. 2017;25(2):346-51.

100. Kirkham AA, Davis MK. Exercise prevention of cardiovascular disease in breast cancer survivors. J Oncol. 2015;2015(917606):1-13.

101. Scott JM, Khakoo A, Mackey JR, Haykowsky MJ, Douglas PS, Jones LW. Modulation of anthracycline-induced cardiotoxicity by aerobic exercise in breast cancer: current evidence and underlying mechanisms. Circulation. 2011;124(5):642-50.

102. Ahmed RL, Thomas W, Yee D, Schmitz KH. Randomized controlled trial of weight training and lymphedema in breast cancer survivors. J Clin Oncol. 2006;24(18):2765-72 
103. Schmitz KH, Ahmed RL, Troxel AB, Cheville A, Lewis-Grant $L$, Smith $R$, et al. Weight lifting for women at risk for breast cancer-related lymphedema: a randomized trial. JAMA. 2010;304(24):2699-705.

104. Ashcraft KA, Peace RM, Betof AS, Dewhirst MW, Jones LW. Efficacy and mechanisms of aerobic exercise on cancer initiation, progression, and metastasis: a critical systematic review of in vivo preclinical data. Cancer Res. 2016;76(14):4032-50

105. Betof AS, Dewhirst MW, Jones LW. Effects and potential mechanisms of exercise training on cancer progression: a translational perspective. Brain Behav Immun. 2013;30(Suppl):S75-87.

106. Dethlefsen C, Pedersen KS, Hojman P. Every exercise bout matters: linking systemic exercise responses to breast cancer control. Breast Cancer Res Treat. 2017:162(3):399-408.

107. Ergun M, Eyigor S, Karaca B, Kisim A, Uslu R. Effects of exercise on angiogenesis and apoptosis-related molecules, quality of life, fatigue and depression in breast cancer patients. Eur J Cancer Care. 2013;22(5):626-37.

108. Galvão DA, Nosaka K, Taaffe D, Peake J, Spry N, Suzuki K, et al. Endocrine and immune responses to resistance training in prostate cancer patients. Prostate Cancer Prostatic Dis. 2008;11(2):160.

109. Hayes BD, Brady L, Pollak M, Finn SP. Exercise and prostate cancer: evidence and proposed mechanisms for disease modification. Cancer Epidemiol Prev Biomark. 2016;25(9):1281-8.

110. Hoffman $P$, editor. Exercise training, tumour metabolism, tumour-host interaction and lactate shuttle theory. 4th Annual Meeting of the International Society of Proton Dynamics in Cancer. Garching: Frontiers in Pharmacology; 2013

111. Idorn M, Hojman P. Exercise-dependent regulation of NK cells in cancer protection. Trends Mol Med. 2016;22(7):565-77.

112. Jones LW, Dewhirst MW. Therapeutic properties of aerobic training after a cancer diagnosis: more than a one-trick pony? JNCl. 2014;106(4):dju042.

113. Koelwyn GJ, Quail DF, Zhang X, White RM, Jones LW. Exercise-dependent regulation of the tumour microenvironment. Nat Rev Cancer. 2017;17(10): 620-32

114. Koelwyn GJ, Wennerberg E, Demaria S, Jones LW. Exercise in regulation of inflammation-immune axis function in cancer initiation and progression. Oncology (Williston Park). 2015;29(12):908-20.

115. Pedersen L, Christensen JF, Hojman P. Effects of exercise on tumor physiology and metabolism. Cancer J. 2015;21(2):111-6.

116. Pudkasam S, Tangalakis K, Chinlumprasert N, Apostolopoulos V, Stojanovska $\mathrm{L}$. Breast cancer and exercise: the role of adiposity and immune markers. Maturitas. 2017;105:16-22.

117. Schadler KL, Thomas NJ, Galie PA, Bhang DH, Roby KC, Addai P, et al. Tumor vessel normalization after aerobic exercise enhances chemotherapeutic efficacy. Oncotarget. 2016;7(40):65429-40.

118. Thomas RJ, Kenfield SA, Jimenez A. Exercise-induced biochemical changes and their potential influence on cancer: a scientific review. Br J Sports Med. 2016;51(8):640-4.

119. Ammitzbø\|l G, Søgaard K, Karlsen RV, Tjønneland A, Johansen C, Frederiksen K, et al. Physical activity and survival in breast cancer. Eur J Cancer. 2016;66:67-74.

120. Bonn SE, Sjölander A, Lagerros YT, Wiklund F, Stattin P, Holmberg E, et al. Physical activity and survival among men diagnosed with prostate cancer. Cancer Epidemiol Prev Biomark. 2015;24(1):57-64.

121. Campbell PT, Patel AV, Newton CC, Jacobs EJ, Gapstur SM. Associations of recreational physical activity and leisure time spent sitting with colorectal cancer survival. J Clin Oncol. 2013;31(7):876-85.

122. Chen X, Lu W, Zheng W, Gu K, Matthews CE, Chen Z, et al. Exercise after diagnosis of breast cancer in association with survival. Cancer Prev Res. 2011;4(9):1409-18.

123. Friedenreich CM, Wang Q, Neilson HK, Kopciuk KA, McGregor SE, Courneya KS. Physical activity and survival after prostate cancer. Eur Urol. 2016;70(4): 576-85.

124. Gunnell AS, Joyce $S$, Tomlin S, Taaffe DR, Cormie P, Newton RU, et al. Physical activity and survival among long-term cancer survivor and noncancer cohorts. Front Public Health. 2017:5:19.

125. Haydon AM, Maclnnis RJ, English DR, Giles GG. Effect of physical activity and body size on survival after diagnosis with colorectal cancer. Gut. 2006;55(1):62-7.

126. Holick CN, Newcomb PA, Trentham-Dietz A, Titus-Ernstoff L, Bersch AJ, Stampfer MJ, et al. Physical activity and survival after diagnosis of invasive breast Cancer. Cancer Epidemiol Prev Biomark. 2008;17(2):379-86.

127. Holmes MD, Chen WY, Feskanich D, Kroenke CH, Colditz GA. Physical activity and survival after breast cancer diagnosis. JAMA. 2005;293(20):2479-86.
128. Ibrahim EM, Al-Homaidh A. Physical activity and survival after breast cancer diagnosis: meta-analysis of published studies. Med Oncol. 2011;28(3):753-65.

129. Kenfield SA, Stampfer MJ, Giovannucci E, Chan JM. Physical activity and survival after prostate cancer diagnosis in the health professionals follow-up study. J Clin Oncol. 2011;29(6):726-32.

130. Meyerhardt JA, Giovannucci EL, Holmes MD, Chan AT, Chan JA, Colditz GA, et al. Physical activity and survival after colorectal cancer diagnosis. J Clin Oncol. 2006;24(22):3527-34.

131. Meyerhardt JA, Giovannucci EL, Ogino S, Kirkner GJ, Chan AT, Willett W, et al. Physical activity and male colorectal cancer survival. Arch Intern Med. 2009;169(22):2102-8

132. Peisch SF, Van Blarigan EL, Chan JM, Stampfer MJ, Kenfield SA. Prostate cancer progression and mortality: a review of diet and lifestyle factors. World J Urol. 2017;35(6):867-74.

133. Richman EL, Kenfield SA, Stampfer MJ, Paciorek A, Carroll PR, Chan JM. Physical activity after diagnosis and risk of prostate cancer progression: data from the cancer of the prostate strategic urologic research Endeavor. Cancer Res. 2011;71(11):3889-95.

134. Van Blarigan EL, Gerstenberger JP, Kenfield SA, Giovannucci EL, Stampfer MJ, Jones LW, et al. Physical activity and prostate tumor vessel morphology: data from the Health Professionals Follow-up Study. Cancer Prev Res. 2015; 8(10):962-7.

135. Galvão DA, Hayne D, Frydenberg M, Chambers SK, Taaffe DR, Spry N, et al. Can exercise delay transition to active therapy in men with low-grade prostate cancer? A multicentre randomised controlled trial. BMJ Open. 2018; 8(4). https://doi.org/10.1136/bmjopen-2018-022331.

136. Ogino S, Lochhead P, Chan AT, Nishihara R, Cho E, Wolpin BM, et al. Molecular pathological epidemiology of epigenetics: emerging integrative science to analyze environment, host, and disease. Mod Pathol. 2013;26(4):465-84.

137. Bruno E, Roveda E, Vitale J, Montaruli A, Berrino F, Villarini A, et al. Effect of aerobic exercise intervention on markers of insulin resistance in breast cancer women. Eur J Cancer Care. 2018;27(2):e12617

138. Demark-Wahnefried W, Campbell KL, Hayes SC. Weight management and its role in breast cancer rehabilitation. Cancer. 2012;118(8):2277-87.

139. Egan K, Cooke N, Kenny D. Living in shear: platelets protect cancer cells from shear induced damage. Clin Exp Metastasis. 2014;31(6):697-704.

140. Garland SN, Johnson B, Palmer C, Speck RM, Donelson M, Xie SX, et al. Physical activity and telomere length in early stage breast cancer survivors. Breast Cancer Res. 2014;16(4):413.

141. Heber S, Volf I. Effects of physical (in) activity on platelet function. Biomed Res Int. 2015;2015:165078.

142. Ludlow AT, Zimmerman JB, Witkowski S, Hearn JW, Hatfield BD, Roth SM. Relationship between physical activity level, telomere length, and telomerase activity. Med Sci Sports Exerc. 2008:40(10):1764-71.

143. Shammas MA. Telomeres, lifestyle, cancer, and aging. Curr Opin Clin Nutr Metab Care. 2011;14(1):28-34.

144. Sharma D, Brummel-Ziedins KE, Bouchard BA, Holmes CE. Platelets in tumor progression: a host factor that offers multiple potential targets in the treatment of cancer. J Cell Physiol. 2014;229(8):1005-15.

145. Regmi S, Fu A, Luo KQ. High shear stresses under exercise condition destroy circulating tumor cells in a microfluidic system. Sci Rep. 2017;7:39975.

146. Wang J, Lü D, Mao D, Long M. Mechanomics: an emerging field between biology and biomechanics. Protein Cell. 2014;5(7):518-31.

Ready to submit your research? Choose BMC and benefit from:

- fast, convenient online submission

- thorough peer review by experienced researchers in your field

- rapid publication on acceptance

- support for research data, including large and complex data types

- gold Open Access which fosters wider collaboration and increased citations

- maximum visibility for your research: over $100 \mathrm{M}$ website views per year

At $\mathrm{BMC}$, research is always in progress.

Learn more biomedcentral.com/submission 